\title{
PENGARUH SEMANGAT DAN DISIPLIN KERJA TERHADAP PRODUKTIVITAS KARYAWAN DALAM PERUSAHAAN DAERAH AIR MINUM (PDAM) KOTA BANDUNG
}

\section{Zulkarnaen}

Politeknik Praktisi Bandung

Email: irhaz_1908@yahoo.com

\begin{abstract}
Abstrak
Penelitian ini bertujuan untuk memafhumi sebanyak apa dampak antusiasme serta disiplin kerja dalam produktivitas karyawan serta kepuasan kerja mengenai kinerja pegawai di Kantor PDAM Kota bandung. Jenis penelitian yang dipakai yaitu penelitian kuantitatif, dimana instrumen penelitian yang digunakan adalah Kuesioner Hasil penelitian semangat serta disiplin kerja di Perusahaan Daerah Air Minum (PDAM) Praja Bandung ialah aspek yang benar-benar penting untuk eskalasi produktivitas kerja dengan cara optimal. Peneliti mengusulkan supaya membangun hubungan yang koheren antara atasan dengan bawahan. Hal ini dibutuhkan supaya dalam aktualisasi pekerjaan antara atasan dengan bawahan ada perasaan kekeluargaan serta kerja sama. Butuh adanya eskalasi rasa percaya diri terhadap semua karyawan dalam melakukan tugas serta kewajibannya, sehingga akibat yang didapatkan lebih optimal antara kualitas serta kuantitasnya. Butuh membangun relasi kerja sama antar pegawai dalam pengimplementasian tugas sehingga tidak ada perasaan dengki dan individualisme.. Dengan begitu beban kerja yang dialokasikan bisa beres dengan perasaan riang sehingga bisa meraih akhir yang optimal.
\end{abstract}

Kata kunci : Semangat Kerja, Disiplin Kerja, Produktivitas Karyawan

\section{Pendahuluan}

Perubahan-perubahan ekonomi dalam globalisasi menyebabkan dampak yang cukup tinggi bagi industri perdagangan, manufaktur ataupun jasa. Persaingan dari domestik ataupun internasional yang semakin diperketat mengakibatkan organisasi dituntut meiliki keunggulan produk, biaya, jasa dan sumber daya manusia untuk mencapai sukses. Dalam sebuah organisasi atau perusahaan dapat meraih kesuksesan karena adanya SDM yang memiliki peranan penting untuk mewujudkan hal-hal tersebut. Sondang P. Siagian mengatakan bahwa "Alat produksi lainnya mustahil disikapi persis dengan manusia, tetapi diperlakukan harus sesuai dengan apa yang diharkati dan martabatnya" (Siagian, 2009). Hasibuan mengemukakan bahwa: "Manusia selalu melakukan keaktifan dalam setiap kegiatan organisasi yakni sebagai pelaku, penentu agar terwujudnya tujuan dalamorganisasi, dan perencana, sehingga manusia 
harus menjadikan sebagai harta yang patut dieskalasi kepraktisan dan produktivitasnya" (Hasibuan, 2001).

Setiap perusahaan menginginkan untuk mendapati karyawan yang aktif dalam kegiatan suatu organisasi atau perusahaan untuk memberikan prestasi pada kerjanya. Dalam produktivitas kerja setinggi-tingginya untuk menjadikan tujuan yang sudah ditentukan sebelumnya. Banyak sekali faktor yang akan mempengaruhi produktivitas yaitu semangat bekerja dan kedisiplinan kerja, tingkat kependidikan, ketrampilan, kesehatan dan gizi, prbuatan dan tingkah laku, penyemangat, kondisi gawai, teknologi, alat dalam produksi, kesempatan bekerja dan kesempatan dalam berprestasi (Ravianto, 1985).

Di samping dikaitkan dengan kemampuan sumber daya manusia, produktivitas juga kerap dikaitkan dengan cara dan sistem yang efisien (Afriandi, 2017). Agar meraih produktivitas yang luhur, pemimpin perusahaan perlu mengatensi antusiasme bekerja. Semangat kerja itu salah satu upaya manusia supaya melakukan pekerjaan tersebut dengan baik. Semangat kinerja pegawai yang maksimal berimbas juga terhadap efisiensi para pekerja dan efektivitas pekerja.

Hal berbeda yang memastikan produktivitas ialah kerja secara disiplin. kehilangan kedisiplinan akan berdampak kepada efisiensi kinerja serta efektivitas tugas pekerjaan. Adanya kedisiplinan diharapkan tugas akan dilaksanakan seefektif mungkin. Jika tidak dapat diterapkan dalam kedisiplinan hingga mungkin maksud yang telah ditentukan tidak akan diraih dengan cara efektif dan efisien (Nitisemito, 1982). Dalam suatu contoh jika suatu perusahaan hanya menekuni perihal edukasi, kemampuan dan teknologi tanpa adanya semangat dan kedisiplin kinerja pegawai, hingga edukasi, kemampuan serta teknologi yang luhur kendatipun tidak akan menciptakan barang yang optimal jika yang bersangkutan tidak bisa memanfaatkannya secara bersungguhsungguhan disiplin dalam pekerjaan yang tinggi.

Selama ini upaya eskalasi keproduktifan lebih sering dilaksanakan melalui eskalasi kognitif serta afektif, padahal untuk mengeskalasikan kognitif serta afektif tersebut butuh dilaksanakannya pelatihan ataupun training yang membutuhkan adanya pengorbanan anggaran (biaya) dan waktu yang cukup banyak. Oleh sebab itu eskalasi antusiasme serta disiplin kerja adalah bagian yang harus dipentingkan dalam upaya meraih keproduktifan yang luhur. 


\section{Metode Penelitian}

Bentuk penelitian ini ialah penelitian kuantitatif, dimana instrumen penelitian yang digunakan adalah Kuesioner. Menurut sugiyono "metode penelitian kuantitatif bisa didefinisikan sebagai langkah penelitian yang dilatarbelakangi oleh filsafat positivisme, dipakai untuk meneliti komunitas ataupun sampel tertentu, kiat pemungutan sampel pada lazimnya dilaksanakan dengan cara random, pengambilan evidensi memakai alat penelitian, analisis data dapat berkarakter kuantitatif ataupun statistik dengan maksud mengetes asumsi yang sudah ditetapkan" (Sugiyono, 2013). Penelitian ini memakai penelitian populasi dikarenakan total responden $<100$. Berdasarkan petunjuk dari pendapat Suharsimi Arikunto menyatakan bahwa: "Sebagai ancer-ancer dalam penentuan sampel, apabila subjek <100, alangkah baiknya dipungut semuanya sehingga penelitian merupakan penelitian populasi”(Arikunto, 2010)

Untuk mengetahui hasil dari penelitian yang dilakukan maka metode analisis data yang digunakan yaitu uji regresi linier berganda, uji simultan dan uji parsial.

\section{Hasil dan Pembahasan}

a. Analisis Regresi Linear Ganda

Berlandaskan hasil perhitungan analisis regresi linear berganda dengan perhitungan komputasi program SPSS diperoleh persamaan regresi, ialah :

$$
\mathrm{Y}=0,126+0,277 \mathrm{X}_{1}+0,208 \mathrm{X}_{2}
$$

Dimana persamaan regresi dua prediktor didapatkan $\mathrm{a}^{1}$ dan $\mathrm{a} 2$ bertanda positif, sehingga bisa disimpulkan sebenarnya satuan skor keproduktifan kinerja diimbasi oleh gairah bekerja sebanyak 0,277 dan disiplin kerja sebanyak 0,208 terhadap konstanta 0,126. Dengan maksud lain, arti dari persamaan di atas ialah :

1) Koefisien konstanta $\mathrm{a}=0,126$ yang berarti bahwa jika tidak ada semangat kerja dan disiplin kerja maka produktivitas kerja sebesar 0,126.

2) Koefisien regresi $X 1$ sebesar 0,277 menyatakan bahwa setiap penambahan satu satuan, maka semangat kerja akan meningkatkan produktivitas kerja sebesar 0,277.

3) Koefisien regresi $X 2$ sebesar 0,208 menyatakan bahwa setiap penambahan satu satuan, maka disiplin kerja akan meningkatkan produktivitas kerja sebesar 0,208. 
b. Uji Simultan

Guna menguji signifikansi dari persamaan regresi linear ganda secara simultan tersebut digunakan uji f yaitu dengan cara harga $F_{\text {hitung }}$ dengan $F_{\text {tabel. }}$. Hasil analisis diperoleh harga $F_{\text {hitung }}=110,066$ pada taraf signifikansi 0,05 dan dengan dk pembilang $=2$ dan tingkat penyebut $=92-2-1=89$ diperoleh harga Ftabel $=$ 3,10. Karena $F_{\text {hitung }}>F_{\text {tabel }}$, sehingga bisa diartikan sebetulnya hipotesis kerja $(\mathrm{Ha})$ yang berbunyi "Ada pengaruh antara gairah kinerja dan disiplin kerja terhadap keproduktivitasan kerja karyawan Perusahaan Daerah Air Minum (PDAM) kabupaten Kudus " diterima.

c. Uji Parsial

Guna menguji signifikansi koefisien regresi untuk variabel semangat kerja yaitu $=$ a1 dan variabel disiplin kerja yaitu $=\mathrm{a} 2$ maka digunakan uji t. Hasil analisis diperoleh harga $\mathrm{t} 1=7,026$ dan $\mathrm{t} 2=4,977$ pada $\square 5 \%$ dengan $\mathrm{dk}=92-2-1=89$ diperoleh harga $t_{\text {tabel }}=1$,99 karena harga $t_{1}$ dan $t_{2}>t_{\text {tabel }}$, maka dapat disimpulkan bahwa variabel bebas $a_{1}$ dan $a_{2}$ dalam penelitian ini bisa menjelaskan variabel terikat yang berada dalam bentuk.

d. Koefisien Determinasi

Besarnya kontribusi sumbangan yang diberikan oleh variabel semangat kerja dan disiplin kerja terhadap produktivitas kerja karyawan Perusahaan Daerah Air Minum (PDAM) kota Bandung secara simultan dapat diketahui dari harga koefisien determinasi ganda atau $\mathrm{r}^{2}$. Besarnya $\mathrm{R}^{2}$ berdasarkan hasil analisis komputer dan program SPSS yaitu sebesar 0,712. Dengan demikian besarnya pengaruh yang diberikan oleh variabel gairah kerja dan disiplin kerja terhadap keproduktivitasan kinerja pegawai Perusahaan Daerah Air Minum (PDAM) kota Bandung secara bersamaan adalah sebesar $71,2 \%$. Sedangkan sisanya yaitu $28,8 \%$ adalah pengaruh aspek lainnya yang tidak diamati dalam penelitian ini.

Besarnya pengaruh masing-masing variabel bebas yaitu semangat kerja $\left(\mathrm{X}_{1}\right)$ serta disiplin kerja $\left(\mathrm{X}_{2}\right)$ pada keproduktivitasan kerja $(\mathrm{Y})$ secara parsial dapat dilihat dari besarnya koefisien determinasi parsial atau $r^{2}$ masing-masing prediktor. Berdasarkan hasil analisis diperoleh hasil seperti terangkum pada tabel berikut : 
Besarnya Pengaruh Variabel Bebas

\begin{tabular}{ccc}
\hline Prediktor & Koefisien Parsial & $\mathrm{r}^{2}$ Determinasi Pasial \\
\hline $\mathrm{X}_{1}$ & 0,597 & 0,356 \\
\hline $\mathrm{X}_{2}$ & 0,467 & 0,218 \\
\hline
\end{tabular}

Ternyata variabel semangat kerja mempunyai pengaruh lebih besar terhadap produktivitas kerja yaitu 35,6\%. Sedangkan disiplin kerja memberikan pengaruh terhadap produktivitas kerja sebesar $21,8 \%$.

Berdasarkan hasil analisis regresi linear berganda dengan memakai komputer program SPSS diperoleh koefisien variabel semangat kerja $\left(\mathrm{X}_{1}\right)$ adalah 0,277 dan koefisien variabel disiplin kerja $\left(\mathrm{X}_{2}\right)$ adalah 0,208 . Sedangkan konstanta sebesar 0,126, dengan demikian bisa didapatkan persamaan regresi sebagai berikut $\mathrm{Y}=0,126+0,277 \mathrm{X}_{1}+0,208 \mathrm{X}_{2}$. Artinya hal ini jika terdapat penambahan ratarata terhadap produktivitas (Y) sebesar 0,277 untuk setiap perubahan satu satuan dalam variabel semangat kerja $\left(\mathrm{X}_{1}\right)$ apabila variabel disiplin kerja $\left(\mathrm{X}_{2}\right)$ dan konstanta dianggap tetap dan ada penambahan rata-rata pada produktivitas (Y) sejumlah 0,208 untuk tiap-tiap perubahan satu-satuan di dalam variabel disiplin kerja $\left(\mathrm{X}_{2}\right)$ apabila variabel semangat kerja $\left(\mathrm{X}_{2}\right)$ dan konstanta diduga tetap. Berdasarkan hasil perhitungan analisis regresi linear berganda dapat diketahui besarnya pengaruh dan sumbangan secara parsial dari setiap variabel independen $\left(\mathrm{X}_{1}\right.$ dan $\left.\mathrm{X}_{2}\right)$ terhadap variabel dependen $(\mathrm{Y})$, sebagai berikut :

1. Pengaruh Semangat Kerja $\left(X_{1}\right)$ terhadap produktivitas Kerja

Berdasarkan hasil perhitungan regresi linear berganda diketahui bahwa besarnya koefisien regresi untuk semangat kerja $\left(X_{1}\right)$ sebesar 0,277. Semangat kerja yang ada di PDAM Kota Bandung pada umumnya sudah terlihat baik, terlihat dari 92 orang responden yang diteliti 89 orang diantaranya telah bekerja dengan baik. Selain itu, Perusahaan Daerah Air Minum (PDAM) praja Bandung perlu memperhatikan semangat kerja karyawan yaitu dengan memberikan perhatian setiap hari kerja atau dikontrol dan pengalokasian hadiah untuk pegawai yang teladan dalam bekerja. Hal ini dilakukan agar karyawan lebih bersemangat dalam bekerja, sehingga meningkatkan produktivitas kerja.

Didasari hasil perhitungan analisis regesi linear berganda, pengujian dengan cara parsial dipahami ternyata variabel semangat kerja $\left(\mathrm{X}_{1}\right)$ didapatkan 
hitung sejumlah 7,026 $>\mathrm{t}_{\text {tabel }}$ sejumlah 1,99 dengan tingkat signifikansi 5\% yang berarti jika ada eskalasi pada gairah bekerja sebesar 7,026 maka akan meningkatkan produktivitas kerja sebanyak satu satuan skor, ini berarti bahwa tiap-tiap adanya perubahan atau penambahan value semangat kerja akan meningkatkan produktivitas kerja. Adapun besarnya sumbangan secara parsial atau koefisien determinasi parsial $\left(\mathrm{r}^{2}\right)$ untuk semangat kerja sebesar 0,356 terhadap produktivitas kerja.

2. Pengaruh Disiplin Kerja $\left(\mathrm{X}_{2}\right)$ terhadap Produktivitas Kerja (Y)

Didasari hasil perhitungan analisis regresi linear berganda diketahui bahwa besarnya koefisien regresi disiplin kerja $\left(\mathrm{X}_{2}\right)$ sebesar 0,208. Disiplin kerja yang ada di PDAM kota Bandung pada umumnya sudah baik, hal ini terlihat dari adanya presensi jam datang maupun jam pulang karyawan yang relatif tepat. Sehingga bisa diambil kesimpulan ternyata disiplin kerja yang baik akan memberikan dampak yang signifikansi terhadap keproduktivitasan pekerjaan pegawai di Perusahaan Daerah Air Minum (PDAM) kota Bandung.

Berdasarkan hasil perhitungan analisis regresi linear berganda dengan pengujian secara parsial diketahui bahwa variabel disiplin kerja $\left(\mathrm{X}_{2}\right)$ didapatkan $\mathrm{t}_{\text {hitung }}$ sejumlah 4,977> dari $\mathrm{t}_{\text {tabel }}$ sebesar 1,99 dengan tingkat signifikansi $5 \%$ yang artinya apabila ada penaikan terhadap disiplin kerja sebesar 4,977 maka akan meningkatkan keproduktivitasan kerja sebanyak satu satuan skor, artinya terdapat makna bahwa setiap ada perubahan ataupun penambahan value disiplin kerja akan menaikan produktivitas kerja. Adapun besarnya sumbangan secara parsial atau koefisien determinasi parsial $\left(\mathrm{r}^{2}\right)$ untuk disiplin kerja sebesar 0,218 terhadap produktivitas kerja.

Melalui uji $\mathrm{F}$ diperoleh $\mathrm{F}_{\text {hitung }}$ sebesar 110,066 pada taraf signifikansi 0,05 dan Ftabel sebesar 3,10 pada taraf signifikansi 0,05. Dengan demikian, $F_{\text {hitung }}(110,066)>F_{\text {tabel }}(3,10)$, berarti regresi linear berganda $Y$ atas $X_{1}$ dan $X_{2}$ bersifat nyata atau dengan kata lain ada dampak semangat kerja dan disiplin kerja terhadap produktivitas kerja karyawan Perusahaan Daerah Air Minum (PDAM) kota Bandung. Berdasarkan hasil perhitungan analisis regresi linear berganda dapat diketahi besarnya sumbangan yang diberikan oleh variabel semangat serta disiplin kerja pada produktivitas kerja pegawai PDAM praja 
Bandung dengan cara bersamaan $\left(\mathrm{r}^{2}\right)$ adalah 0,712 atau $71,2 \%$, hal ini berarti produktivitas sebesar $71,2 \%$ diakibatkan oleh semangat kerja dan disiplin kerja dan sisanya sebesar $28,8 \%$ diimbasi oleh aspek lainnya yang tidak diamati ataupun diluar model penelitian.

\section{Kesimpulan}

1. Adanya pengaruh positif antara disiplin dan semangat kerja pada keproduktivitasan kinerja pegawai di PDAM Kota Bandung. Hal ini bisa diketahui dari hasil perhitungan pada lampiran 12 halaman 98 yang diperoleh Fhitung sebesar 110,066 sedangkan $\mathrm{F}_{\text {tabel }}$ dengan $\mathrm{df}=3,10$ terhadap taraf signifikansi $5 \%=0,05$ jadi tampak bahwa $\mathrm{F}_{\text {hitung }}>\mathrm{F}_{\text {tabel }}$ sehingga bisa disimpulkan yakni hipotesis kerja (Ha) diterima. Besarnya sumbangan yang diberikan variabel semangat disiplin kerja dan kerja pada produktivitas kerja sebanyak $71,2 \%$ dan sisanya $28,8 \%$ dipengaruhi oleh variabel yang lainnya dan tida diungkapkannya pada penelitian ini.

2. Didasarkan pada hasil uji parsial dapat diartikan yakni variabel semangat kerja memiliki pengaruh pada produktivitas kerja dengan sumbangan parsial sebesar $35,6 \%$. Sedangkan variabel disiplin kerja dengan sumbangan parsial sebesar 21,8\%. Dengan itu dapat diambil kesimpulan bahwa variabel kedisiplinan kerja memiliki pengaruh yang lebih tinggi terhadap produktivitas pekerja karyawan PDAM kota bandung dibandingkan dengan variabel semangat kerja. 


\section{BIBLIOGRAFI}

Afriandi, S. (2017). Meningkatkan Produktivitas Kerja Di Perusahaan Jasa Survey. Syntax Literate; Jurnal Ilmiah Indonesia, 2(2), 133-143.

Arikunto, S. (2010). Prosedur penelitian. Jakarta: rineka cipta.

Hasibuan, M. S. P. (2001). Manajemen Sumber Daya manusia, Edisi Revisi, Cetakan. Ke empat, Bumi Aksara, jakarta.

Nitisemito, A. S. (1982). Manajemen personalia:(managemen sumber daya manusia). Ghalia Indonesia.

Ravianto, J. (1985). Produktivitas dan manusia Indonesia (Vol. 3). Lembaga Sarana Informasi Usaha dan Produktivitas.

Siagian, S. P. (2009). Manajemen Sumber Daya Manusia. Cetakan ke Dua Belas. PT Bumi Aksara. Jakarta.

Sugiyono, P. D. (2013). Metode Penelitian Manajemen. Bandung: Alfabeta, CV. 